\title{
A comparison of sap flow and eddy fluxes of water vapor from a boreal deciduous forest
}

\author{
Edward H. Hogg, ${ }^{1}$ T. Andrew Black, ${ }^{2}$ Gerry den Hartog, ${ }^{3}$ Harold H. Neumann, ${ }^{3}$ \\ Reiner Zimmermann, ${ }^{4}$ Patrick A. Hurdle, ${ }^{1}$ Peter D. Blanken, ${ }^{2}$ Zoran Nesic, ${ }^{2}$ \\ Paul C. Yang, ${ }^{2}$ Ralf M. Staebler, ${ }^{3}$ Kyle C. McDonald, ${ }^{4}$ and Ram Oren ${ }^{5}$
}

\begin{abstract}
Water flux to the atmosphere was measured from a mature stand of aspen (Populus tremuloides Michx.) in Saskatchewan, Canada, as part of the Boreal EcosystemAtmosphere Study (BOREAS). Diurnal and seasonal changes in transpiration were monitored using two sap flow techniques and were compared against the difference between eddy correlation measurements of water vapor flux made above and below the aspen canopy. The three methods showed similar diurnal and seasonal trends in water flux, although sap flow lagged the eddy correlation measurements by about 1 hour diurnally due to changes in water storage within the trees. During the growing season, all methods showed a linear increase in midday transpiration with above-canopy vapor pressure deficit (VPD) up to $\sim 1 \mathrm{kPa}$, beyond which transpiration was relatively constant (VPD 1-2.5 kPa). A similar relationship was obtained when total daily transpiration was plotted against mean daytime VPD. The results are consistent with other observations that stomatal conductance of the aspen canopy decreases at high VPD. The complementary benefits of simultaneous monitoring of canopy transpiration by both eddy correlation and sap flow measurements are discussed.
\end{abstract}

\section{Introduction}

The Boreal Ecosystem-Atmosphere Study (BOREAS) is a large-scale, international field experiment that aims to improve understanding of the interactions between the boreal forest biome and the atmosphere in order to clarify their roles in global change [Sellers et al., 1995a]. Most of the research is being focused within two large study areas in western Canada: the Southern Study Area near Prince Albert, Saskatchewan, and the Northern Study Area near Thompson, Manitoba.

One of the major processes being studied in BOREAS is evapotranspiration (water vapor flux) from different vegetation types and its control by environmental and ecophysiological factors. In 1994, measurements of water vapor flux (along with $\mathrm{CO}_{2}$ in most cases) were made at 10 tower sites, located in trembling aspen (Populus tremuloides Michx.), jack pine (Pinus banksiana Lamb.), black spruce (Picea mariana (Mill.) BSP.), and fen ecosystems.

One of the difficulties in comparing tree-based, ecophysiological responses with tower-based flux measurements made above the forest canopy is that the latter may include a significant contribution by the soil and understory vegetation. However, at the mature aspen site in the Southern Study Area, water vapor and $\mathrm{CO}_{2}$ fluxes were partitioned between the tree and the understory components through tower-based, eddy correlation measurements at different heights [Black et al.,

\footnotetext{
'Canadian Forest Service, Edmonton, Alberta, Canada.

${ }^{2}$ University of British Columbia, Vancouver, Canada.

${ }^{3}$ Atmospheric Environment Service, Downsview, Ontario, Canada.

${ }^{4}$ Jet Propulsion Laboratory, Pasadena, California.

${ }^{5}$ Duke University, Durham, North Carolina.

Copyright 1997 by the American Geophysical Union.

Paper number 96JD03881.

0148-0227/97/96JD-03881\$09.00
}

1996]. This was feasible because of a large and well-defined vertical separation between the tree canopy and the understory shrub layer, which were each relatively uniform and dominated by a single species (trembling aspen and beaked hazelnut, Corylus cornuta Marsh., respectively). The measurements were made using the eddy correlation technique, by several of us in the tower flux (TF-1 and TF-2) science team, as part of the 1994 BOREAS field campaign [Sellers et al., 1995a].

In the present paper, we compare the 1994 tower-based measurements of water vapor flux from the aspen canopy at this site with concurrent measurements of sap (i.e., water) flow within individual stems of aspen in the same stand. Two different methods of determining sap flow were used: the heat pulse method (terrestrial ecology (TE) team, group TE-7) and the constant power method (remote sensing science (RSS) team, group RSS-17). The objectives of this paper were (1) to compare measurements of diurnal and seasonal change in aspen water flux and (2) to use the three methods to examine relative responses of aspen transpiration to above-canopy vapor pressure deficit. We also identify issues that may cause difficulty in making interscale comparisons of transpiration measurements from individual trees versus the stand level in trembling aspen forests.

\section{Methods}

\subsection{Study Site Description}

The site $\left(53^{\circ} 38^{\prime} \mathrm{N}, 106^{\circ} 12^{\prime} \mathrm{W}\right.$, elevation $\left.600 \mathrm{~m}\right)$ is located within Prince Albert National Park, Saskatchewan, in the southern boreal forest of western Canada. It is in an extensive, mostly pure stand of trembling aspen about 70 years old, with a stem density of about $800 /$ ha. Aspen clones (patches of genetically identical trees) are readily distinguishable because of differences in bark characteristics and phenology. The aspen trees are mostly $18-22 \mathrm{~m}$ tall, and stem diameters at $1.3 \mathrm{~m}$ 
height are $0.15-0.30 \mathrm{~m}$. The height to the base of the aspen canopy is about $15 \mathrm{~m}$. The understory shrub layer is dominated by beaked hazelnut about $2 \mathrm{~m}$ tall. Leaf area index reached a seasonal maximum (July 1994) of 2.3 for the tree canopy and 3.3 for the understory shrub layer [Blanken et al., this issue]. The soil has a silty-clay texture with $0.08-0.10 \mathrm{~m}$ layer of organic material at the surface, and aspen roots penetrate to a depth of about $0.6 \mathrm{~m}$. Mean temperatures of the warmest and coldest months are $16^{\circ} \mathrm{C}$ (July) and $-21^{\circ} \mathrm{C}$ (January), respectively (at Waskesui Lake, $30 \mathrm{~km}$ north of the site at $530 \mathrm{~m}$ elevation). Mean annual precipitation is $463 \mathrm{~mm}$, of which 300 $\mathrm{mm}$ falls as rain between May and September [Environment Canada, 1982].

\subsection{Water Vapor Fluxes by Eddy Correlation (TF-1 and TF-2)}

Fluxes were measured at two heights using the eddy correlation technique, as described by Black et al. [1996]. Water vapor flux above the canopy was measured at the $39.5 \mathrm{~m}$ height from a mast mounted on a $37 \mathrm{~m}$ tower, while fluxes above the shrub layer were measured at the $4 \mathrm{~m}$ height on a second $6 \mathrm{~m}$ tower located $40 \mathrm{~m}$ away from the first tower. Threedimensional sonic anemometer-thermometers were used at both levels (Kaijo-Denki DAT-310 and Gill Instruments 1012R2 Solent, respectively). Fluctuations in water vapor concentrations were measured (along with $\mathrm{CO}_{2}$ ) using temperature-controlled infrared gas analyzers (LI-COR 6262) at both heights. Additional measurements were made with an open path $\mathrm{H}_{2} \mathrm{O}$ analyzer (Campbell-Scientific $\mathrm{KH} 2 \mathrm{O}$ hygrometer) at the $4 \mathrm{~m}$ height. Data were processed according to Black et al. [1996], and mean fluxes were calculated for each $30 \mathrm{~min}$ period. Continuous measurements were made from early October to mid-November 1993 (not reported here) and from early February to late September 1994. Evapotranspiration from the aspen canopy was determined as the difference of water vapor fluxes measured at the two heights. During the summer months the water vapor flux measured above the shrub layer accounted for $23 \%$ of the total for the forest as a whole [Black et al., 1996; Blanken et al., this issue].

\subsection{Sap Flow by Constant Power Method (RSS-17)}

The constant power method [Granier, 1987] was used to monitor sap flow in nine aspen trees in a clone located within $50 \mathrm{~m}$ of the main flux tower. Tree characteristics were representative of the stand as a whole, with stem diameters at $1.3 \mathrm{~m}$ height of $0.16-0.29 \mathrm{~m}$. The apparatus for each tree consisted of two cylindrical probes, each $2 \mathrm{~mm}$ in diameter, that were inserted into the sapwood to a depth of $20 \mathrm{~mm}$ below the vascular cambium. The upper probe was installed at a height of about $1.6 \mathrm{~m}$ and was continuously heated at a constant power of $0.2 \mathrm{~W}$. The lower, unheated probe was installed about 100 $\mathrm{mm}$ directly below the heated probe. All probes were located on the north side of trees and covered with a plastic shield to minimize assymmetrical temperature fluctuations within the xylem. The temperature difference between the heated and unheated probes was monitored by a data logger every $60 \mathrm{~s}$, and averages were reported every half hour. Sap flux density $(S, \mathrm{~mm} / \mathrm{h}$, i.e., volume flow rate per unit sapwood crosssectional area) was determined using the following empirical relationship from Granter [1987]:

$$
S=428\left[\left(\Delta T_{m}-\Delta T\right) / \Delta T_{m}\right]^{[23 !}
$$

where $\Delta T$ is the temperature difference between the two probes at the time of measurement, and $\Delta T_{m}$ is the maximum temperature difference over each $24 \mathrm{~h}$ period. Typically, $\Delta T_{m}$ is recorded at night, just prior to dawn, when it is assumed that $S=0$ [Granier, 1987]. Probes were installed on October 26, 1993 (DOY 299), and continuous measurements were made from February 16, to October 5, 1994 (DOY 47-278).

\subsection{Sap Flow by Heat Pulse Method (TE-7)}

The heat pulse velocity (HPV) method [Marshall, 1958; Swanson, 1983, 1994] was used to monitor sap flow of six aspen at a site located about $1 \mathrm{~km}$ east of the main flux tower, in the same extensive aspen stand and having similar characteristics (0.17-0.27 $\mathrm{m}$ diameter and 17-22 $\mathrm{m}$ height). Three trees from each of two clones were selected for monitoring. Probes were installed on May 26, 1994 (DOY 146) during the spring period of rapid leaf expansion in the aspen canopy. The two clones were named EL (early leafing) and LL (late leafing) based on the phenological differences noted on this date.

Our implementation of the method used differential, chromel-constantan thermocouples sharing a common reference junction and placed symmetrically $7.5 \mathrm{~mm}$ above and below the heater. The thermocouple reference junction was located $25 \mathrm{~mm}$ laterally from the heater, and all thermocouple junctions were located at a sapwood depth of $15 \mathrm{~mm}$. The heater had a power output of $0.2 \mathrm{~W} / \mathrm{mm}$ along its length and was inserted to a depth of $50 \mathrm{~mm}$. All probe elements had a diameter of $1.6 \mathrm{~mm}$, and holes of the same diameter were drilled using a steel template. Probes were located at a height of $\sim 1.3 \mathrm{~m}$ on the north side of the tree and were thermally insulated by wrapping with white polyethylene packing material. The six trees were monitored by two Campbell Scientific $21 \mathrm{X}$ data loggers, powered by batteries and a solar panel. Measurements of the temperature increase at the upper $\left(T_{11}\right)$ and lower $\left(T_{l}\right)$ thermocouples were taken $60 \mathrm{~s}$ following a $4 \mathrm{~s}$ heat pulse (total power $40 \mathrm{~J}$ ), every 3 hours from May 26 to October 20, 1994 (DOY 146-293). On each tree, probes were removed and replaced with new probes at a different location on the same tree, once during the summer (four trees on DOY 192 and two trees on DOY 209). Sap flux density $(S, \mathrm{~m} / \mathrm{s})$ was calculated using the following equation derived from Marshall [1958]:

$$
S=\frac{k_{w w} \ln \left(T_{u} / T_{1}\right)}{x c_{p w} \rho_{w^{w}}}
$$

where $x$ is the spacing between the heater and each thermocouple $(0.0075 \mathrm{~m})$ and where $c_{p w}$ and $\rho_{w}$ are the specific heat and density of sap (i.e., values for water of $4180 \mathrm{~J} / \mathrm{kg} /{ }^{\circ} \mathrm{C}$ and $\left.1000 \mathrm{~kg} / \mathrm{m}^{3}\right)$. The thermal conductivity of active sapwood $\left(k_{n_{n}}\right)$ was estimated at $0.38 \mathrm{~J} / \mathrm{m} / \mathrm{s} /{ }^{\circ} \mathrm{C}$ based on

$$
k_{w}=k_{n} M \rho_{h} / \rho_{w}+k_{t w}\left(1-M \rho_{h} / \rho_{w^{\prime}}\right)
$$

where $k_{w}$ is the thermal conductivity of water $\left(0.60 \mathrm{~J} / \mathrm{m} / \mathrm{s} /{ }^{\circ} \mathrm{C}\right)$, $\rho_{b}$ is the typical live bulk density of aspen sapwood $\left(370 \mathrm{~kg} / \mathrm{m}^{3}\right)$ [Peterson and Peterson, 1992], and $M$ is the typical sapwood moisture content of $1.0 \mathrm{~kg}$ moisture per kilogram dry mass. The reported variation in aspen moisture content from 0.75 to $1.25 \mathrm{~kg} / \mathrm{kg}$, i.e., $100 \pm 25 \%$ [Gibbs, 1939], would lead to $\pm 9 \%$ error in $k_{s w}$ and resultant estimates of $S$. The longitudinal thermal conductivity of dry wood $\left(k_{d w}\right)$ was taken to be 0.248 $\mathrm{J} \mathrm{m} / \mathrm{s} /{ }^{\circ} \mathrm{C}$ based on $\rho_{b}$, and the resultant void volume [Siau, 1971]. For purposes of presentation, values of $S$ from (2b) were expressed in millimeter per hour (i.e., multiplied by $3.6 \times$ $\left.10^{6}\right)$. 
Heat transfer theory indicates that the interruption of the sap stream by probes results in an underestimation of the true sap flux density. For our implementation, wound width was estimated to be $2.0-2.2 \mathrm{~mm}$, including a $0.2-0.3 \mathrm{~mm}$ zone of disturbed sapwood on each side of the holes following drilling [Swanson and Whitfield, 1982; Barrett et al., 1995]. Simulations using a two-dimensional numerical model similar to Swanson and Whiffield [1981] indicated that with our implementation a correction factor $(a)$ of about $2.0( \pm 15 \%)$ is warranted to obtain the actual sap flux density $\left(S^{*}\right)$, where

$$
S^{*}=a S
$$

A similar underestimation of $45 \%$ (i.e., $a=1.8$ ) was observed by Cohen et al. [1981] for their implementation of the heat pulse method.

For each of the two clones, measurements of $S^{*}$ were multiplied by the stand sapwood area to ground area ratio (SA) to give estimates of canopy transpiration. SA was determined as the product of $\mathrm{BA}$ and FSA, where $\mathrm{BA}$ is the basal area to ground area ratio of aspen stems (at $1.3 \mathrm{~m}$ height) in one $10 \times$ $10 \mathrm{~m}$ plot centered on each clone, and FSA is the fraction of BA occupied by sapwood. FSA was calculated using two radial increment cores from each of four trees per clone (total of 16 radii). The zone of active sapwood within increment cores was recognized from staining by a methylene blue in methyl hydrate dye.

\subsection{Supporting Measurements}

A wide variety of other measurements were made at the site during the BOREAS experiment (for details, see Black et al. [1996]). In the present analysis we calculated vapor pressure deficits [Jones, 1992, p. 110] from half-hourly averages of air temperature and vapor pressure at the $39 \mathrm{~m}$ height. These measurements were taken using an aspirated platinum resistance thermometer and a dew point hygrometer. Precipitation was measured using a weighing Belfort rain guage and a tipping bucket rain guage. Soil water potential was measured half hourly using gypsum blocks (depths of $0.06,0.16$, and $0.46 \mathrm{~m}$ ). Soil water content was measured every $1-3$ days using timedomain reflectometry (TDR) with a Tektronix, Inc. 1602 cable tester and G. S. Gabel Corp. segmented TDR probes (depth $0-1.2 \mathrm{~m}$ ) and gravimetrically (depth $0-0.10 \mathrm{~m}$ ).

\section{Results and Discussion}

\subsection{Seasonal Changes in Daily Water Flux}

Both the sap flow and the tower-based, eddy correlation measurements (Figure 1) showed a rapid increase in water flux from the aspen canopy in late May 1994 (DOY 142-151) during the period of rapid leaf expansion when the leaf area index increased from 0.5 to 1.6 [Black et al., 1996; Blanken et al., this issue]. Water flux was generally greatest from mid-June to early August, when the aspen leaf area index was near its seasonal maximum of 2.3 and declined in September during the period of leaf senescence and abscission.

The pattern of short-term variation in mean daily sap flux density $(S)$ was generally similar among the aspen clones monitored, but differences were noted in the magnitude and broad seasonal pattern (Figure 1a). On DOY 147, $S$ by the heat pulse method was about twice as high in the early-leafing (EL) clone compared to the late-leafing (LL) clone (EL mean, $21 \mathrm{~mm} / \mathrm{h}$, range $19-28 \mathrm{~mm} / \mathrm{h}$; LL mean, $11 \mathrm{~mm} / \mathrm{h}$, range $8-14 \mathrm{~mm} / \mathrm{h}) . S$
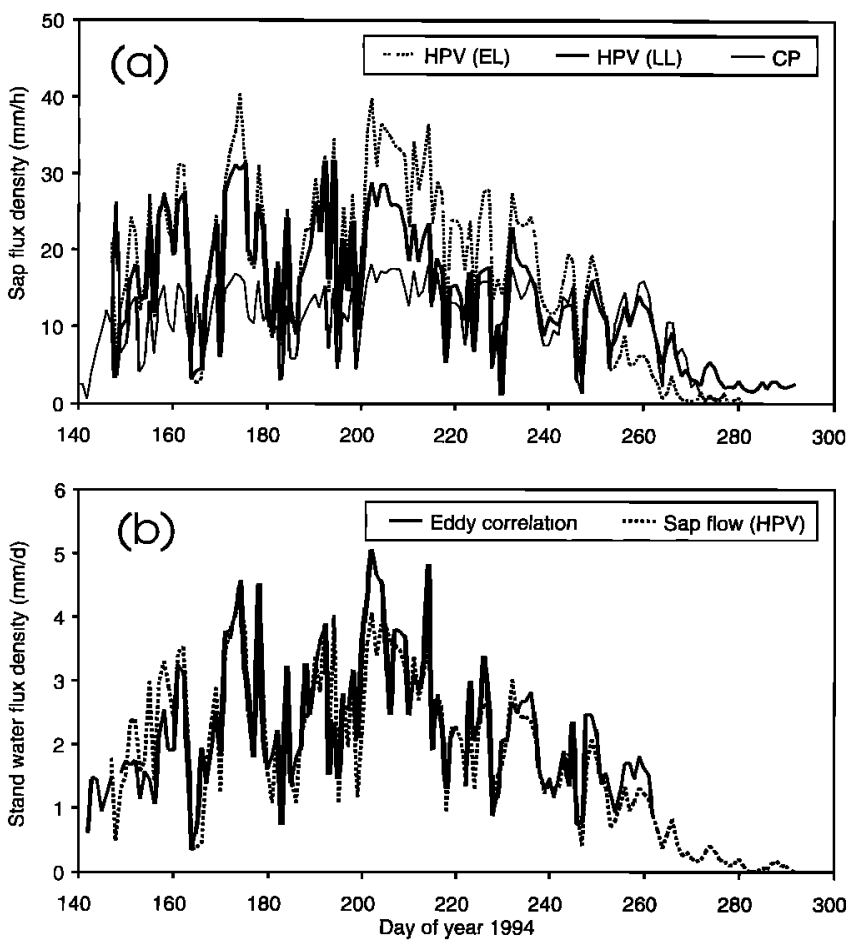

Figure 1. Daily water flux for trembling aspen during the 1994 growing season. The aspen was almost fully leafed out by the end of May (DOY 151), while senescence and leaf fall occurred in September (DOY 250-270). (a) Uncorrected flux density within sapwood of individual trees $(S)$, as measured by the heat pulse velocity (HPV) method (EL, and LL clones, mean of three trees per clone) and the constant power (CP) method (mean of nine trees in one clone). (b) Water flux density at the stand level, measured by two eddy correlation systems above and below the aspen canopy, and estimated from the HPV method (mean of EL and LL clones with scaling based on stand sapwood area and sap flux density $\left(S^{*}\right)$ corrected for flow interruption by probes with $a=2.0$ ).

was generally greater in the EL clone during the summer but declined sharply relative to the LL clone in early September. This is consistent with our observation that the EL clone had lost most of its leaves by DOY 253 (September 10), whereas the LL clone continued to have a full, green canopy beyond this date.

In the aspen clone monitored by the constant power method, $S$ was generally only about half of that measured by the heat pulse method in June and July (Figure 1a) but remained near midsummer levels until mid-September. In contrast, the clones monitored by the heat pulse method showed a gradual decline in $S$ starting in late July. This resulted in a greater similarity in the magnitudes of $S$ for the two sap flow methods during the latter part of the growing season. In particular, the magnitude of $S$ in the LL clone was very similar to that measured by the constant power method in August and September.

For each of the two clones monitored by the heat pulse method, daily transpiration was estimated from $S^{*}$ (as described in section 2.4). The basal area (BA) ratio was 0.0038 and 0.0063 for the EL and LL clones, respectively, and the fraction of sapwood (FSA) was 0.51 for both clones, based on measurements made in July 1994. Thus the SA ratio was 0.0020 for EL and 0.0032 for LL. On the basis of the above, with $a=$ 2.0 , total estimated transpiration over the growing season 


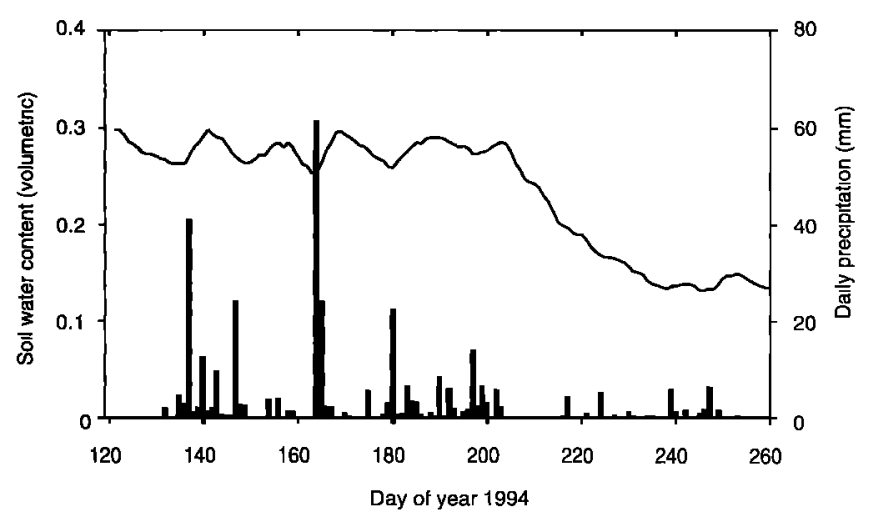

Figure 2. Soil water content $(0-0.3 \mathrm{~m}$ depth, time-domain reflectrometry (TDR) measurements) and daily precipitation during the 1994 growing season.

(DOY 147-261) was 222 and $297 \mathrm{~mm}$ for EL and LL, respectively. The average estimated transpiration of $254 \mathrm{~mm}$ for the two clones combined was similar to the total water flux of 266 $\mathrm{mm}$ based on the tower flux eddy correlation systems. Variation in stand water flux density among days and throughout the season also showed good agreement between the heat pulse and eddy correlation methods (Figure 1b). It should be noted that the measurements made by eddy correlation included both transpiration and evaporation of intercepted rainfall from the aspen canopy. We did not measure canopy evaporation directly, but it is probably about $8 \%$ of total rainfall, based on the results of Clements [1971] in an aspen forest in Ontario, Canada, with similar stand characteristics and precipitation patterns.

The constant power method would give much lower estimates (not shown) if the results were scaled to give transpiration on a stand basis. This is partly because the magnitude of $S$ measured by the constant power method was generally smaller than for the heat pulse method (Figure 1a). Also, when the results from heat pulse method were scaled to give estimates of stand transpiration, a correction factor $(a=2.0)$ was applied to $S$ to account for sap flow interruption by probes, but such a correction is not applicable to the constant power method. Much closer correspondence has been obtained elsewhere, involving comparisons between the constant power method and the other measurements of transpiration [Granier et al., 1990; Diawara et al., 1991]. Early installation of the probes prior to spring thaw may have resulted in reduced thermal contact between probes and xylem following freezethaw cycles. However, there was no evidence of a further decline in $S$ during the growing season, and lower thermal contact should not have affected relative responses.

The late summer decline in stand water flux density (Figure 1b) was accompanied by a gradual decrease in volumetric soil moisture content (at depth of $0-0.3 \mathrm{~m}$ ) from $\sim 0.28$ to 0.14 , during a period of scant rainfall (Figure 2). Soil water potential at the $0.46 \mathrm{~m}$ depth was near $-0.03 \mathrm{MPa}$ in June and July but by mid-August (DOY 230) had fallen to $-0.4 \mathrm{MPa}$ (gypsum block sensor). Drought stress may have been a factor in causing the overall late-season decline in transpiration, particularly in the EL clone, where foliage color had begun to change in mid-August. In contrast, the aspen clone monitored by the constant power method showed no evidence of such a decline, possibly due to deeper rooting or locally moister soils (not measured but expected if transpiration rates were actually lower in this clone).

\subsection{Mean Diurnal Trends and Changes in Water Storage}

We selected the period from June 9 to August 17 (DOY 160-229) as the "peak growing season" for an analysis of mean diurnal changes in water flux. This corresponds to the period following full expansion of the aspen canopy in all clones but prior to the onset of critically low soil moisture in late August. Also during this period, the leaf area index of the understory hazelnut was near its seasonal maximum value and was relatively stable [Black et al., 1996].

Mean diurnal changes in water flux during the peak growing season are shown in Figure 3, expressed as a ratio of the hourly flux to the mean hourly flux over this 70 day period. The eddy correlation measurements show that mean water flux from the aspen canopy reached a maximum near or slightly after solar noon (1305 central standard time (CST) at this location). Low values were recorded from 2100 to 0600 , when global solar radiation was $<50 \mathrm{~W} / \mathrm{m}^{2}$. An analysis of the diurnal eddy correlation measurements, in relation to vapor pressure deficit, solar radiation, and canopy conductance, is given by Blanken et al. [this issue].

Mean diurnal changes in sap flow lagged changes in tower-
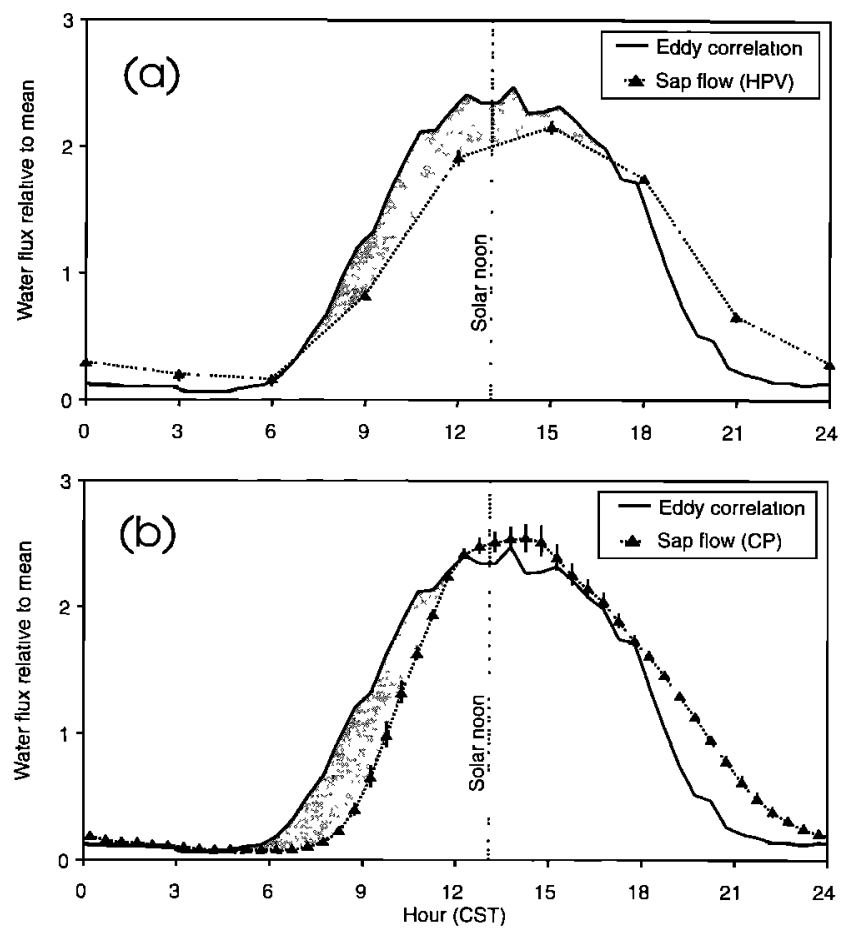

Figure 3. Mean diurnal water flux for trembling aspen from June 9 to August 17, 1994 (DOY 160-229), expressed as a ratio of the hourly flux to the overall mean hourly flux recorded during this period. Comparisons of diurnal responses obtained by the eddy correlation method against sap flow by the heat pulse (HPV) method every 3 hours (a) and the CP method every 0.5 hours (b) are shown. For sap flow measurements, vertical bars indicate standard errors in relative diurnal responses, based on $N=6$ trees for HPV and $N=9$ trees for CP. Shaded areas indicate where evapotranspiration from the aspen canopy exceeded the rate of upward water flux in the sapwood (at $1.3 \mathrm{~m}$ height). Mean solar noon occurs at the site at 1305 CST. 
based water flux, both using the heat pulse (Figure 3a) and constant power (Figure 3b) methods. With the heat pulse method the diurnal pattern was similar to that recorded by eddy correlation, but nighttime fluxes were relatively higher. This could be partly a result of slight errors in probe spacing with the heat pulse method. However, significant nighttime sap flow can occur in aspen, based on our observation that sap flow was greatest on nights with high vapor pressure deficits (see Figure 4). With the constant power method, nighttime sap flow was low and tended to increase more slowly in the early morning. Both sap flow methods showed a more gradual decline in diurnal water flux between 1800 and 2100 , compared with the eddy correlation measurements.

The mean diurnal change in water storage within the aspen canopy and stem (above $-1.5 \mathrm{~m}$ height) can be derived from Figure 3 and estimates of mean daily transpiration, assuming that the mean net change in water storage from one day to the next is small (i.e., mean daily transpiration = mean daily sap flow). First, diurnal changes in water storage can be expressed as a fraction of mean daily transpiration by summing the continuous positive deviations of water flux (shaded areas) from the tower versus sap flow. On the basis of this, mean diurnal changes in water storage using heat pulse (Figure 3a) and the constant power method (Figure $3 b$ ) were 13.5 and $11.6 \%$, respectively, of mean daily aspen transpiration for DOY $160-$ 229 . From the eddy correlation measurements, mean transpiration over this period was $2.43 \mathrm{~mm} / \mathrm{d}$ based on a total water flux from the aspen canopy of $186 \mathrm{~mm}$ and assuming that $8 \%$ of the rainfall recorded during this period $(16 \mathrm{~mm})$ was intercepted and evaporated. This gives estimated mean diurnal changes in water storage of 0.33 and $0.28 \mathrm{~mm}$ for the two sap flow methods, which is equivalent to about 1 hour of midday transpiration. For comparison, the aboveground pool of readily available water in conifer stands with comparable characteristics can be as great as $0.5 \mathrm{~mm}$ or about one quarter of daily transpiration [Schulze et al., 1985; Diawara et al., 1991; Cienciala et al., 1994].

\subsection{Water Flux in Relation to Vapor Pressure Deficit}

Another useful means of comparing the three methods is to examine the ability of each to detect relative transpiration responses to changes in environmental conditions. In the following analysis we present a comparison of responses to abovecanopy vapor pressure deficit (VPD) during the peak growing season, when soil moisture was not limiting. The VPD was expected to be the most important environmental factor governing transpiration of this forest, especially during the midday period when solar radiation is not limiting on most days [see Blanken et al., this issue].

For sap flow by the heat pulse method the readings at 1500 CST were greatest on the average (Figure 3a) and were thus considered to be representative of midday conditions. With the constant power method, midday was also represented by a measurement period near the diurnal maximum, from 14.5 to 1500 CST. For vapor pressure deficit (VPD) and midday water flux based on eddy correlation, we used the average of the four half-hourly measurements between 1300 and 1500 CST. This period was chosen to broadly compensate for the 1 hour diurnal phase lag of sap flow measurements and to smooth the apparently random nature of variability among adjacent halfhourly eddy correlation measurements (Figure 4).

When plotted against midday VPD (Figure 5a), both sap flow methods showed an approximately linear increase in mid-
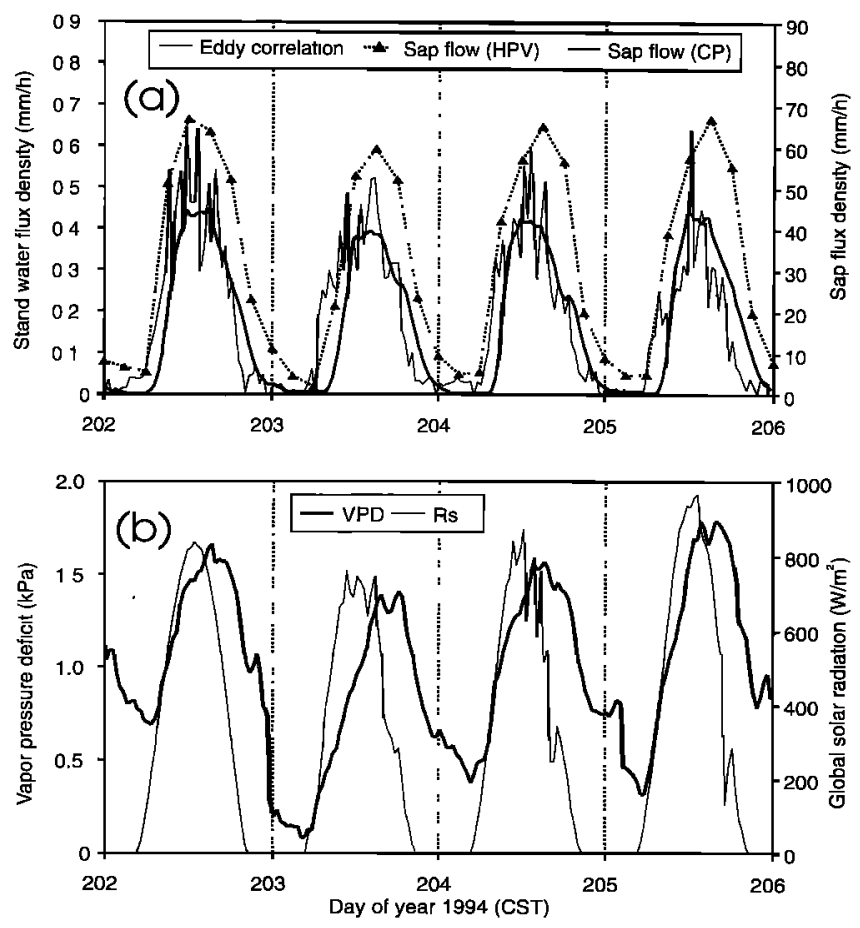

Figure 4. (a) Water flux for July 21-24, 1994 (DOY 202205), as measured by eddy correlation (tower) and by two sap flow methods $(S)$. For sap flow, mean values are shown for the CP method (nine trees) and the heat pulse method (EL and LL clones, six trees). (b) Environmental conditions recorded at the 39-m height during this period.

day sap flux density $(S)$ up to $\sim 1 \mathrm{kPa}$, but for VPD greater than this, $S$ was relatively constant. For the heat pulse method this relationship was particularly striking when the results from both clones ( $N=6$ trees) were used to estimate canopy transpiration (Figure 5b). The magnitude of the transpiration estimates based on heat pulse was similar to that from eddy correlation, and the latter method also showed a tendency for water flux to remain constant for VPD $>1 \mathrm{kPa}$. For all three methods the slope of the relationship between flux and VPD was not significantly different from zero, if only the days with VPD $>1 \mathrm{kPa}$ are considered $\left(N=28\right.$ days, range of $r^{2}$ from 0.01 to 0.05 ). Thus fluxes of water from the aspen canopy were nearly the same for days with VPD $>1.5 \mathrm{kPa}$, compared with days with VPD between 1.0 and $1.5 \mathrm{kPa}$ (Table 1 ).

When total daily water flux ( 2400 period beginning at 0100 CST, i.e., solar midnight) was plotted against mean daytime VPD (0700-1900 CST), there was also a tendency for fluxes to level off for VPD $>1 \mathrm{kPa}$ (Figure 6). For constant power method and the eddy correlation measurements the slope of the relationship for VPD $>1 \mathrm{kPa}$ was not significantly different from zero ( $N=21$ days, $r^{2}$ from 0.01 to 0.03 ). In contrast, the heat pulse method indicated a slight increase in water flux for $\mathrm{VPD}>1 \mathrm{kPa}\left(r^{2}=0.26, p<0.05\right)$, but the slope over this range was less $(0.9 \mathrm{~mm} / \mathrm{d} / \mathrm{kPa})$ than for $\mathrm{VPD}<1 \mathrm{kPa}(3.1$ $\mathrm{mm} / \mathrm{d} / \mathrm{kPa}$ ).

The tendency for canopy transpiration to level off at high VPD has been reported in studies conducted elsewhere, including tropical rain forest [Meinzer et al., 1993; Granier et al., 1996] as well as temperate forests and woodlands [e.g., Lopushinsky, 1986; Price and Black, 1989; Goulden and Field, 1995]. When observed in forests with a high aerodynamic con- 

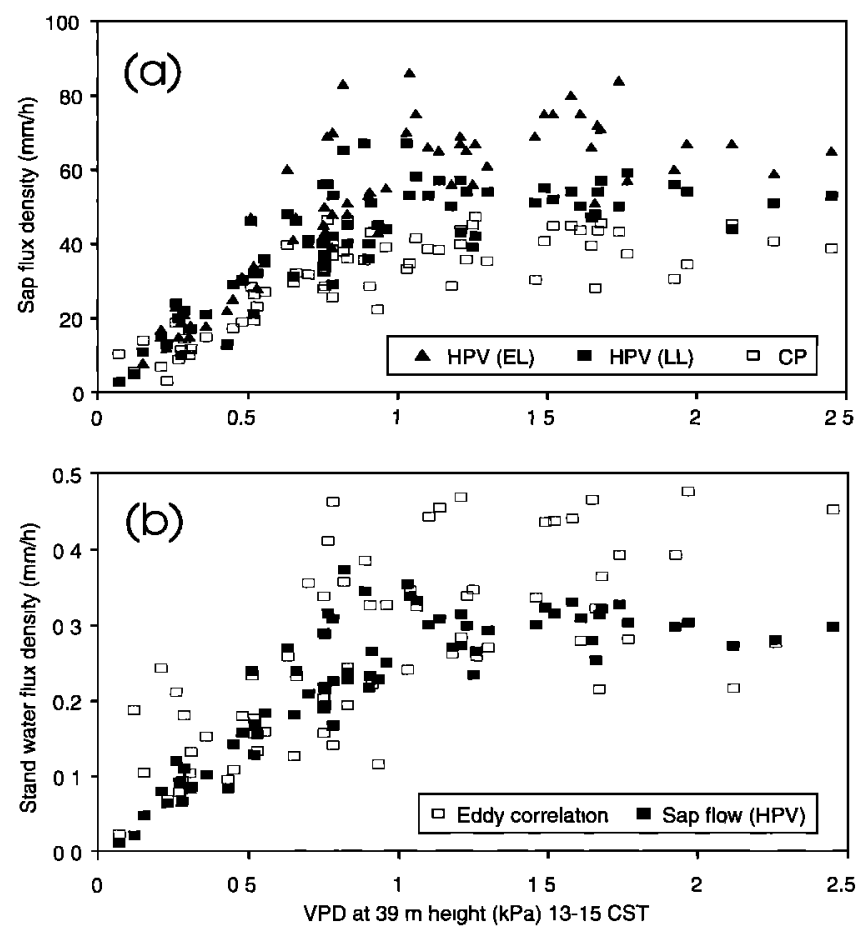

Figure 5. Midday water flux for trembling aspen on 70 days during the 1994 growing season, in relation to the above canopy (39 m height) vapor pressure deficit (VPD). Flux measurements are as described in Figure 1. Sap flow comparisons are based on measurements at $1500 \mathrm{CST}$ for the HPV method and 14.5-1500 CST for the CP method. For measurements of VPD and water vapor flux density by eddy correlation method (above-minus below-canopy readings), averages for the period 1300-1500 CST are shown.

ductance, such a response indicates gradual closure of stomata as the VPD of ambient air (e.g., above canopy) increases. This interpretation should be applicable to the boreal aspen site examined in the present study, which because of canopy roughness and small leaf size (30-50 mm in length and width) has a high $(\sim 50-200 \mathrm{~mm} / \mathrm{s})$ aerodynamic conductance [Blanken et $a l$., this issue]. More specifically, our observation of a constant midday transpiration rate over a range of VPD $>1 \mathrm{kPa}$ suggests that stomatal conductance was inversely proportional to VPD over this range. It is also consistent with the results of analysis by Blanken et al. [this issue] that aspen canopy con-

Table 1. Comparison of Midday Water Fluxes for Trembling Aspen Under Different Ranges of Vapor Pressure Deficit for DOY 160-229

\begin{tabular}{|c|c|c|c|c|}
\hline & \multicolumn{4}{|c|}{ Vapor Pressure Deficit, $\mathbf{k P a}$} \\
\hline & $0.0-0.5$ & $0.5-1.0$ & $1.0-1.5$ & $>1.5$ \\
\hline Number of days & 15 & 27 & 14 & 14 \\
\hline \multicolumn{5}{|c|}{ Sap flux denstty $(S, m m / h)$} \\
\hline Constant power method & 12 & 33 & 38 & 40 \\
\hline Heat pulse method (EL clone) & 17 & 49 & 68 & 68 \\
\hline Heat pulse method (LL clone) & 17 & 42 & 52 & 52 \\
\hline \multicolumn{5}{|c|}{ Stand Water Flux Denstty $(\mathrm{mm} / \mathrm{h})$} \\
\hline Eddy correlation & 0.13 & 0.25 & 0.34 & 0.36 \\
\hline Sap flow (heat pulse) & 0.08 & 0.23 & 0.30 & 0.30 \\
\hline
\end{tabular}

ductance in this forest decreases exponentially with VPD. Field measurements of leaf stomatal conductance in trembling aspen conducted elsewhere [McCaughey and lacobelli, 1994] are also consistent with these relationships.

Since water flux from the aspen canopy is governed largely by the leaf stomata, it may seem surprising that stomatal responses were tuned in such a way as to produce relatively constant transpiration rates over a range of VPD. It is possible that such a result could be explained by leaf level models that link stomatal responses to photosynthesis rates and environmental conditions at the leaf surface [e.g., Collatz et al., 1991]. An alternative explanation is that stomatal conductance was being constrained by the need for aspen to maintain leaf water potentials above the point where catastrophic cavitation of xylem would occur [Tyree and Sperry, 1988; Spery and Pockman, 1993; Goulden and Field, 1995]. Under these circumstances the hydraulic resistance from soil to leaf would ultimately determine the maximum transpiration rate that could be sustained by the canopy [cf. Meinzer and Grantz, 1991]. Further study of this mechanism could be helpful in making refinements to models of transpiration, at spatial scales ranging from single trees to the landscape [e.g., Jarvis, 1976; McNaughton and Jarvis, 1991; Monteith, 1995; Sellers et al., 1995b; Williams et al., 1996].

\subsection{Scaling Issues and Sources of Error}

In this study, the three methods of estimating canopy water flux gave broadly similar results, in terms of relative responses to above-canopy VPD. Such agreement should strengthen confidence in the observed overall responses to VPD, since the potential sources of error are very different and largely inde-
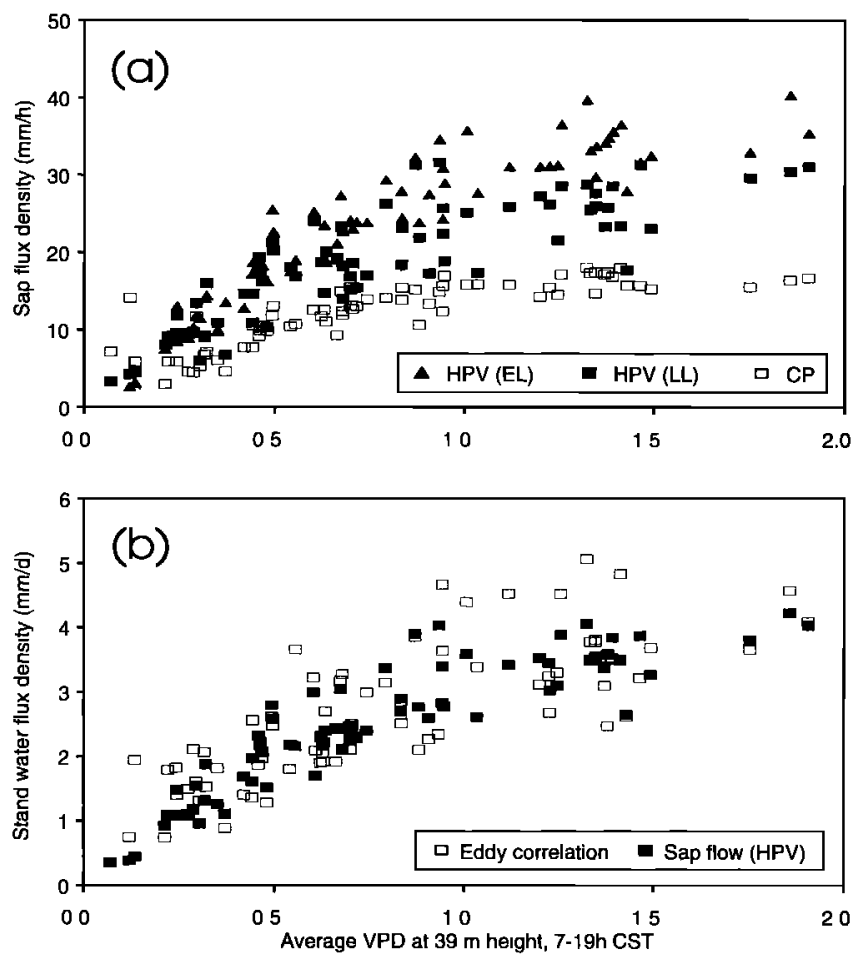

Figure 6. Daily average sap flux density (a) and total daily water flux density from the aspen stand (b) for 70 days during the 1994 growing season, in relation to the average daytime (0700-1900 CST) vapor pressure deficit (39 m height). Flux measurements are as described in Figure 1. 
pendent between the tower-based and sap flow methods. However, there were often considerable differences in estimates of water flux among the three methods, in terms of relative seasonal and diurnal responses, degree of short-term variation, and absolute quantitative estimates.

It is apparent that for clonal species such as aspen, differences in clone phenology and physiological functioning can be a major problem in relating leaf- or tree-level measurements to larger-scale measurements. This problem appeared to be most critical during the periods of spring leafing and late season leaf senescence, when differences in clone phenology were most apparent. The results also suggest increased variation among clones during periods of moisture stress. In contrast, clonal variation should have had a smaller effect on above-canopy eddy correlation measurements, because tower fluxes would normally represent spatial averaging from many clones.

For mean diurnal responses changes in water storage largely accounted for the 1 hour lag between sap flow and eddy correlation measurements, as discussed above. Differences in relative diurnal responses were even observed between the two sap flow methods (Figure 3). This could reflect differences among sites and clones, but the lower early morning values recorded by the constant power method might be a result of changes in heat storage [Grime et al., 1995]. With both methods, there are also potential errors in precisely defining conditions of zero sap flow. Since significant sap flow may occur on nights with high VPD [Green et al., 1989], predawn sap flow should not be assumed to be zero except when VPD is very small.

Sap flow readings can also be affected by changes in sapwood moisture content (see section 2.4), but on a diurnal basis, such changes are expected to be small. The total quantity of moisture in the aspen at the site is $>4 \mathrm{~mm}\left(>40 \mathrm{~m}^{3} / \mathrm{ha}\right.$ ), based on a minimum stem volume of $120 \mathrm{~m}^{3} / \mathrm{ha}$ [Halliwell and Apps, 1996]. Since the estimated diurnal change in water storage within the aspen stand was about $0.3 \mathrm{~mm}$ (section 3.2 ), the mean percentage change in moisture content of sapwood xylem should be $<8 \%$, leading to a potential error of $<3 \%$ in estimates of sap flux density (section 2.4). Even this estimate of error is probably higher than necessary, since the calculation does not include diurnal changes in moisture content of the foliage.

For obtaining quantitative measurements of water flux at the canopy level, tower-based micrometeorological methods have clear advantages over other methods, partly because they are generally nonintrusive and because they integrate fluxes over large areas. Sap flow measurements, in contrast, are made within small regions of sapwood in individual trees, leading to difficulties in "scaling up" to the canopy level. One problem is that the rate of sap (water) flux in the vicinity of probes may not be representative of the average flux across the crosssectional area of sapwood in single trees, because of radial and azimuthal variation in flow rates [Cohen et al., 1985; Hatton et al., 1995; Swanson, 1994]. Sap flux density may also differ significantly even among adjacent trees for a wide variety of reasons and large sample sizes may be needed to obtain a reliable statistical sample. As indicated in section 2.4, results are also influenced by changes in sapwood moisture content and the interruption of sap flow by probes. Losses of sensitivity can also occur during the growing season due to progressive wounding responses [Swanson and Whitfield, 1981; Swanson, 1983]. This did not appear to be a major problem in the present study, but with the heat pulse method, we noticed a $10-15 \%$ increase in sap flux densities for several days following probe changes in midsummer (DOY 192 and 209), which may account for some of the scatter in Figure 5.

Accurate determinations of canopy transpiration from sap flow measurements can be achieved, but quantitative reliability can only be assured with a carefully conducted, intensive experimental design [e.g., Hatton et al., 1995]. Although we obtained comparable estimates of canopy transpiration from one of the sap flow methods (heat pulse), caution would be advised in applying this technique as the sole means of making quantitative measurements. With the constant power method, sap flux measurements were lower than expected, based on the eddy correlation method, indicating a possible reduction in the sensitivity of probes installed prior to spring thaw.

One of the difficulties with the eddy correlation measurements was the high degree of short-term variation which did not appear to be related to changes in key environmental factors such as VPD and solar radiation (Figure 4). This is also apparent in the relationship between midday water flux and VPD (Figure 5b), where both sap flow methods gave generally more stable and consistent values. This was partly because of evaporation from the aspen canopy during and following rainfall events, which was not recorded by the sap flow methods (e.g., four outlier days with VPD $<0.3 \mathrm{kPa}$ and tower water flux density $>0.15 \mathrm{~mm} / \mathrm{h}$ in Figure $5 \mathrm{~b}$ ). Another factor to consider is that for eddy correlation, the areas of forest (footprint) being measured differ greatly for the above- and belowcanopy measurements, and both are affected by wind speed and direction. Although the aspen forest was relatively uniform within $500 \mathrm{~m}$ in all directions from the tower site, there was variability in the degree of energy closure (i.e., sum of sensible and latent heat flux versus available energy) among adjacent half-hourly measurements. These issues are examined in more detail by Blanken et al. [this issue].

\section{Conclusions}

All three methods showed that midday transpiration from the aspen canopy has a striking tendency to remain constant for above-canopy VPD ranging from 1.0 to $2.5 \mathrm{kPa}$. Since midday aerodynamic conductance is high, such constancy in transpiration rates reflects gradual stomatal closure as VPD increases beyond $1 \mathrm{kPa}$, which is supported by other studies of stomatal responses in this species. The maximum transpiration rate of the aspen canopy may be indirectly governed by hydraulic resistance from soil to leaf, and the need to avoid xylem cavitation.

The results of this study indicate the benefits of using different methods to simultaneously measure transpiration from the aspen canopy: Eddy flux correlation measurements made above and below the canopy are generally superior in providing quantitative, daily, and seasonal estimates of water flux at the stand level. Another clear advantage of eddy flux correlation is its versatility in measuring fluxes other than water vapor (e.g., $\mathrm{CO}_{2}$, sensible heat, trace gases, etc.). Flux estimates can be also independently verified by determining the degree of energy closure. On dry days without morning dew, all of the water flux is due to transpiration, but over longer periods with dew and rainfall events, the measured water flux also includes an evaporation component.

Sap flow measurements on individual trees can be subject to considerable bias when "scaled up" to the stand level but appear to be more stable than eddy correlation over periods 
ranging from $<1$ hour to several days. Such stability arises largely from their insensitivity to atmospheric conditions and because the locations being sensed are fixed (in contrast to the variable footprint of forest being sensed by eddy correlation). Another important advantage of sap flow methods is that they can provide a more direct measurement of tree transpiration; that is, evaporation of intercepted water is not included. However, because of changes in water storage, sap flow measurements tend to be lagged relative to eddy correlation measurements and environmental conditions (by about 1 hour for mean diurnal responses in the present study, but see Hollinger et al. [1994]).

The use of both techniques simultaneously is mutually helpful in identifying problems and methodological weaknesses, because the potential errors in each technique are different and generally independent. This can strengthen the reliability and usefulness of functional relationships that would be obtained by either method alone.

Acknowledgments. The authors from UBC (TF-1) gratefully acknowledge funding from the Natural Science and Engineering Research Council (NSERC) of Canada, including a Collaborative Special Project grant in support of universities participating in BOREAS and an operating grant to T. A. Black. Funding was provided by Canada's Green Plan to the authors from AES (TF-2) and CFS (TE-7). Work by the authors at JPL (RSS-17) was conducted under contract to the National Aeronautics and Space Administration, and we thank JoBea Way at JPL for strongly supporting this study. Field operations were made possible by the support of personnel at Prince Albert National Park, especially Mary Dalman, Murray Heap, and Paula Pacholek. We also thank S. G. Chen, J. Deary, G. Edwards, J. Fuentes, B. Goodison, T. Herzog, E. Kanemasu, X. Lee, M D. Novak, C. Russell, I. Simpson, G. Thurtell, and others withın BOREAS for on-site assistance and support. Useful comments on the manuscript were provided by $D$. Halliwell, D. T. Price, and I. D. Campbell (CFS).

\section{References}

Barrett, D. J., T. J. Hatton, J. E. Ash, and M. C. Ball, Evaluation of the heat pulse velocity technique for measurement of sap flow in rainforest and eucalypt forest species of southeastern Australia, Plant Cell Environ., 18, 463-469, 1995.

Black, T. A., et al., Annual cycles of water vapour and carbon dioxide fluxes in and above a boreal aspen forest, Global Change Biol., 2, 219-229, 1996.

Blanken, P. D., T. A. Black, P. C. Yang, H. H. Neumann, Z. Nesic, R. Staebler, G. den Hartog, M. D. Novac, and X. Lee, Energy blance and canopy conductance of a boreal aspen forest: Partitioning overstory and understory components, J. Geophys. Res., this issue.

Cienciala, E., H. Eckersten, A. Lindroth, and J.-E. Hallgren, Simulated and measured water uptake by Picea abıes under non-limiting soil water conditions, Agric. For. Meteorol., 71, 147-164, 1994.

Clements, J. R., Evaluating summer rainfall through a multilayered largetooth aspen community, Can. J. For. Res., 1, 20-31, 1971.

Cohen, Y., M. Fuchs, and G. C. Green, Improvements of the heat pulse method for determining sap flow in trees, Plant Cell Environ., 4, 391-397, 1981.

Cohen, Y., F. M. Kelliher, and T. A. Black, Determination of sap flow in Douglas-fir trees using the heat pulse technique, Can. J. For. Res., $15,422-428,1985$.

Collatz, G. J., J. T. Ball, C. Grivet, and J. A. Berry, Physiological and environmental regulation of stomatal conductance, photosynthesis and transpiration: A model that includes a laminar boundary layer, Agric. For. Meteorol., 54, 107-136, 1991.

Diawara, A., D. Loustau, and P. Berbigier, Comparison of two methods for estimating the evaporation of a Pinus pinaster (Ait.) stand: Sap flow and energy balance with sensible heat flux measurements by an eddy covariance method, Agric. For. Meteorol., 54, 49-66, 1991.

Environment Canada, Canadian climatic normals 1951-1980, in Tem- perature and Precipttation, Pratne Provinces, 429 pp., Atmos. Environ. Serv., Downsview, Ontario, Canada, 1982.

Gibbs, R. D., Studies in tree physiology, I, General introduction: Water contents of certain Canadian trees, Can. J. Res., 17(C), 460-482, 1939.

Goulden, M. L., and C. B. Field, Three methods for monitoring the gas exchange of individual tree canopies: Ventılated-chamber, sap-flow and Penman-Monteith measurements on evergreen oaks, Funct. Ecol., 8, 125-135, 1995.

Granier, A., Evaluation of transpiration in a Douglas-fir by means of sap flow measurements, Tree Physiol., 3, 309-320, 1987.

Granier, A., V. Bobay, J. H. C. Gash, J. Gelpe, B. Saugier, and W. J. Shuttleworth, Vapour flux density and transpiration rate comparisons in a stand of Maritime pine (Ptnus ptnaster Ait.) in Les Landes forest, Agnc. For. Meteorol., 51, 309-319, 1990.

Granier, A., R. Huc, and S. T. Barigah, Transpiration of natural rain forest and its dependence on climatic factors, Agric. For. Meteorol., $78,19-29,1996$

Green, S. R., K. G. McNaughton, and B. E. Clothier, Observations of nighttime water use in kiwifruit vines and apple trees, Agric. For. Meteorol., 48, 251-261, 1989.

Grime, V. L., J. I. L. Morison, and L. P. Simmonds, Sap flow measurements from stem heat balances: A comparison of constant with variable power methods, Agric. For. Meteorol., 74, 27-40, 1995.

Halliwell, D., and M. J. Apps, BOREAS biometry and auxilliary sites, in Overstory and Understory data, version 2, Can. For. Serv., Edmonton, 1996.

Hatton, T. J., S. J. Moore, and P. H. Reece, Estimating stand transpiration in a Eucalyptus populnea woodland with the heat pulse method: Measurement errors and sampling strategies, Tree Physiol., 15, 219-227, 1995.

Hollinger, D. Y., F. M. Kelliher, E.-D. Schulze, and B. M. M. Köstner, Coupling of tree transpiration to atmospheric turbulence, Nature, $371,60-62,1994$.

Jarvis, P. G., The interpretation of the variation in leaf water potential and stomatal conductance found in canopies in the field, Philos. Trans. R. Soc. London, Ser. B, 273, 593-610, 1976.

Jones, H. G., Plants and Microclimate, a Quanttative Approach to Environmental Plant Physiology, 2nd ed., 428 pp., Cambridge Unıv. Press, New York, 1992.

Lopushinsky, W., Seasonal and diurnal trends of heat pulse velocity in Douglas-fir and ponderosa pine, Can. J. For. Res., 16, 814-821, 1986.

Marshall, D. C., Measurement of sap flow in conifers by heat transport, Plant Physiol., 33, 385-396, 1958.

McCaughey, J. H., and A. Iacobelli, Modelling stomatal conductance in a northern deciduous forest, Chalk River, Ontario, Can J. For. Res., 24, 904-910, 1994.

McNaughton, K. G., and P. G. Jarvis, Effects of spatial scale on stomatal control of transpiration, Agric. For. Meteorol., 54, 279-301, 1991.

Meinzer, F. C., and D. A. Grantz, Coordination of stomatal, hydraulic, and canopy boundary layer properties: Do stomata balance conductances by measuring transpiration?, Physiol. Plant., 83, 324-329, 1991.

Meinzer, F. C., G. Goldstein, N. M. Holbrook, P. Jackson, and J. Cavelier, Stomatal and environmental control of transpiration in a lowland tropical forest tree, Plant Cell Envtron. 16, 429-436, 1993.

Monteith, J. L., Accommodation between transpiring vegetation and the convective boundary layer, J. Hydrol., 166, 251-263, 1995.

Peterson, E. B., and N. M. Peterson, Ecology, management, and use of aspen and balsam poplar in the Prairie Provinces, Canada, Spec. Rep. 1, For. Can., North. For. Res. Cent., Edmonton, 1992.

Price, D. T., and T. A. Black, Estimation of forest transpiration and $\mathrm{CO}_{2}$ uptake using the Penman-Monteith equation and a physiological photosynthesis model, in Proceedings of Workshop on Estimation of Areal Evapotranspiration, IAHS Publ. 177, Vancouver, B. C., 1989.

Schulze, E.-D., J. Cermak, R. Mayssek, M. Penka, R. Zimmermann, F. Vasicek, W. Gries, and J. Kucera, Canopy transpiration and water fluxes in the xylem of the trunk of Larx and Picea trees-A comparison of xylem flow, porometer and cuvette measurements, Oecolog $ı$, 66, 475-483, 1985.

Sellers, P. J., et al., The Boreal Ecosystem-Atmosphere Study (BOREAS): An overview and early results from the 1994 field year, Bull. Am. Meteorol. Soc., 76, 1549-1577, 1995a.

Sellers, P. J., M. D. Heiser, F. G. Hall, S. J. Goetz, D. E. Strebel, S. B. Verma, R. L. Desjardins, P. M. Schuepp, and J. I. MacPherson, 
Effects of spatial variability in topography, vegetation cover, and soil moisture on area-averaged surface fluxes: A case study using the FIFE 1989 data, J. Geophys. Res., 100, 25,607-25,629, 1995 b.

Siau, J. F., Flow in Wood, Syracuse Wood Sci. Ser., vol. 1, 131 pp., Syracuse Univ. Press, Syracuse, N. Y., 1971.

Sperry, J. S., and W. T. Pockman, Limitation of transpiration by hydraulic conductance and xylem cavitation in Betula occidentalis, Plant Cell Environ., 16, 279-287, 1993.

Swanson, R. H., Numerical and experimental analyses of implantedprobe heat pulse velocity theory, Ph.D. thesis, 298 pp., Univ. of Alberta, Edmonton, 1983.

Swanson, R. H., Significant historical developments in thermal methods for measuring sap flow in trees, Agric. For. Meteorol., 72, 113132, 1994.

Swanson, R. H., and D. W. A. Whitfield, A numerical analysis of heat pulse velocity theory and practice, J. Exp. Bot., 32, 221-239, 1981.

Tyree, M. T., and J. S. Sperry, Do woody plants operate near the point of catastrophic xylem dysfunction caused by dynamic water stress?, Plant Physiol., 88, 574-580, 1988.

Williams, M., E. B. Rastetter, D. N. Fernandes, M. L. Goulden, S. C.
Wofsy, G. R. Shaver, J. M. Melillo, J. W. Munger, S.-M. Fan, and K. J. Nadelhoffer, Modelling the soil-plant-atmosphere continuum in a Quercus-Acer stand at Harvard Forest: The regulation of stomatal conductance by light, nitrogen and soil/plant hydraulic properties, Plant Cell Environ., in press, 1996.

T. A. Black, P. D. Blanken, Z. Nesic, and P. C. Yang, University of British Columbia, Vancouver, B. C., Canada V6T $1 Z 4$.

G. den Hartog, H. H. Neumann, and R. M. Staebler, Atmospheric Environment Service, Downsview, Ontario, Canada M3H 5T4.

E. H. Hogg and P. A. Hurdle, Canadian Forest Service, 5320-122 Street, Edmonton, Alberta, Canada T6H 3S5.

K. C. McDonald and R. Zimmermann, Jet Propulsion Laboratory, 4800 Oak Grove Drive, Pasadena, CA 91109.

R. Oren, Duke University, Box 90328, Durham, N. C. 27728.

(Received May 1, 1996; revised December 4, 1996; accepted December 4, 1996.) 